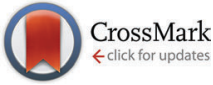

Cite this: Phys. Chem. Chem. Phys., 2017, 19, 9028

Received 14th February 2017 Accepted 5th March 2017

DOI: 10.1039/c7cp00982h

rsc.li/pccp

\section{On the relation between carbonyl stretching frequencies and the donor power of chelating diphosphines in nickel dicarbonyl complexes $\dagger$}

\author{
Marco Fusè, ${ }^{a}{ }^{a}$ Isabella Rimoldi, ${ }^{b}$ Edoardo Cesarotti, ${ }^{b}$ Sergio Rampino*a and \\ Vincenzo Barone ${ }^{a}$
}

\begin{abstract}
The relation between spectroscopic observables and the detailed metal-ligand bonding features in chelation complexes is addressed using both experimental and state-of-the-art theoretical and computational methods. We synthesized and characterized a set of six nickel dicarbonyl complexes of general formula $\left[\mathrm{Ni}(\mathrm{CO})_{2}(\mathrm{PP})\right]$, where PP is an atropoisomeric chelating diphosphine ligand. The analysis of the obtained experimental data and the basicity and oxidative potentials of the free ligands suggests a close relation between the donor ability of the chelating ligand and the carbonyl stretching frequencies observed in the complexes. We then use theory to unravel the detailed mechanisms of chelation-bond formation in terms of partial charge flows between the molecular orbitals of the fragments. By extending the promising, recently published natural orbitals for chemical valence/charge displacement (NOCV/CD) analysis scheme we provide a thorough, quantitative description of the several charge fluxes following the metal-ligand bond formation and demonstrate that the carbonyl stretching frequencies in the considered complexes selectively respond to the $\sigma$-donation charge flow from the phosphorus lone pairs of the ligands, with the frequency shift being in quantitative correlation with the extent of the ligand-to-metal charge transfer.
\end{abstract}

\section{Introduction}

In homogeneous catalysis, bidentate phosphines are a successful and widely used class of ligands which have proved their worth over many decades. ${ }^{1}$ After coordination at the metal center, the chelating structure is able to impose a relatively rigid environment, tuning the electron richness of the metal and, in turn, the reactivity of the coordinated complex. For these reasons, understanding the properties of the metal-ligand chemical bond is of fundamental importance for rationalizing and predicting the catalytic efficiency of these complexes and for developing new catalysts.

As far as monophosphines are concerned, the most widely used experimental probe of the electronic effects of phosphine ligands at the metal center is Tolman's electronic parameter (TEP). ${ }^{2,3}$ TEP is based on the position of the $A_{1}$ carbonyl

\footnotetext{
${ }^{a}$ Scuola Normale Superiore, Piazza dei Cavalieri 7, 56126 Pisa, Italy.

E-mail: marco.fuse@sns.it, sergio.rampino@sns.it; Fax: +39050 509 430; Tel: +39050 509682

${ }^{b}$ Dipartimento di Scienze Farmaceutiche, Università di Milano, Via Golgi 19, 20133 Milano, Italy

$\dagger$ Electronic supplementary information (ESI) available: Antisymmetric $\nu_{\mathrm{CO}}^{\exp } v s$. $\mathrm{p} K_{\mathrm{a}}$ and $E^{0}$, calculated $\beta$ angles, correlation between $\mathrm{CT}_{\mathrm{don}}$ and $\nu_{\mathrm{CO}}^{\text {calc }}$, experimental ${ }^{1} \mathrm{H},{ }^{13} \mathrm{C}\left\{{ }^{1} \mathrm{H}\right\},{ }^{31} \mathrm{P}\left\{{ }^{1} \mathrm{H}\right\}$ NMR spectra of complexes, and optimized geometries of the complexes. See DOI: 10.1039/c7cp00982h
}

stretching-frequency band in the spectrum of $\left[\mathrm{Ni}(\mathrm{CO})_{3} \mathrm{~L}\right]$, where $\mathrm{L}$ is a phosphine ligand, with respect to the stretching vibration of free $\mathrm{CO}$ as recorded in the gas phase, which has a value of $2143 \mathrm{~cm}^{-1}$. ${ }^{4}$ In classical mononuclear carbonyl complexes, the $A_{1}$ carbonyl stretching frequency lies in the range $2125-1850 \mathrm{~cm}^{-1,5}$ and the observed red shift with respect to free $\mathrm{CO}$ is taken as a measure of the overall donor ability of L. Though the validity of such approach has been recently questioned (see for instance ref. 6, where evidence is given for intramolecular interactions interfering with the carbonyl stretching response to the ligandmetal interaction) and alternative, more sophisticated parameters have been proposed, ${ }^{7}$ TEP still represents a traditional and widespread method for assessing and comparing the electronic properties of the ligands. ${ }^{8}$ Unfortunately, TEP provides no information on the detailed features of the metal-ligand bond in terms of its Dewar-Chatt-Duncanson $\sigma$ donation and $\pi$ back-donation components. To this purpose, several theoretical studies, mainly in the framework of density functional theory (DFT), have been reported in the last few decades (see for example ref. 9-13). These are based on a number of successful bond-analysis schemes such as natural bond orbitals (NBO), charge-decomposition analysis (CDA), energy-decomposition analysis (EDA) and atoms in molecules (AIM).

As for bidentate phosphines, a parameter which has been so far widely used to predict the reactivity of diphosphine 
complexes is the bite angle $(\beta),{ }^{14,15}$ defined as the $\mathbf{P}-\mathrm{M}-\mathrm{P}$ angle. It is worth noting here that the bite angle, however, accounts for both a steric effect of the diphosphine ligand on the metal center, and an electronic one (affecting the overlap between the metal and ligand orbitals), ${ }^{16}$ which can hardly been disentangled. Though a number of other general descriptors, often based on computational investigations, are also available, ${ }^{17-19}$ as a matter of fact there are few examples of studies of the donor/acceptor properties of chelating diphosphines (see for instance ref. 20 and 21) or, more in general, chelating ligands (see ref. 22 and 23).

Prompted by the already quoted landmark work of Tolman on monophosphines, ${ }^{2}$ in this work we decided to synthesize a series of $\mathrm{Ni}(0)$ dicarbonyl complexes of general formula $\left[\mathrm{Ni}(\mathrm{CO})_{2}(\mathrm{PP})\right]$, where PP is a chelating diphosphine, and to address the relation between the carbonyl stretching frequencies and the detailed features of the metal-ligand chemical bond. As for the PP ligands, we focused on a set of six heteroaromatic atropoisomeric ligands, abbreviated hereinafter as bitiop, binap, bitianp, tmbitianp, bifurp and bimip (see a synoptic scheme of their structures in Fig. 1). ${ }^{24-27}$ Atropoisomeric phosphorus ligands have been established as being extremely efficient in the asymmetric hydrogenation of a wide range of substrates, particularly aryl and heteroaryl ketones. ${ }^{28-30}$ The series considered in this work has been chosen due to the reliable reaction with $\left[\mathrm{Ni}(\mathrm{CO})_{4}\right]$ avoiding the formation of mixture or side products. Moreover, atropoisomeric ligands feature a similar bite angle in the nickel dicarbonyl complexes and this minimizes the differences in terms of geometric and steric effects permitting to better focus on the purely electronic ones.

The article is structured as follows. After providing the experimental methods and computational details (Section 2), we first examine the relation between the observed carbonyl stretching frequencies and some experimental estimates of the electronic properties of the free ligands such as basicity and electrochemical oxidative potentials (Section 3.1). The correlation between these quantities suggests a close relation between the donor ability of the chelating ligand and the carbonyl stretching frequencies observed in the complexes. Then, based on density functional theory (DFT) calculations, we carry out a thorough theoretical analysis (Section 3.2) of the metal-ligand chemical bond by means of a powerful, recently proposed analysis scheme, namely the natural orbitals for chemical valence/charge displacement (NOCV/CD) method. ${ }^{31}$ Through the NOCV/CD analysis we give a quantitative, spatially detailed description of the several charge fluxes following the metalligand bond formation and show that the carbonyl stretching frequencies in the considered complexes selectively respond to the $\sigma$-donation charge flow from the phosphorus lone pairs of the ligands, with the frequency shift being in quantitative correlation with the ligand-to-metal transferred charge. We draw conclusions and outline perspectives for future work in the last section (Section 4).

\section{Experimental methods and computational details}

\subsection{Experimental methods}

All manipulations involving air-sensitive materials were performed in an inert atmosphere by using standard Schlenk line techniques in nitrogen glassware. All solvents used were anhydrous by fresh

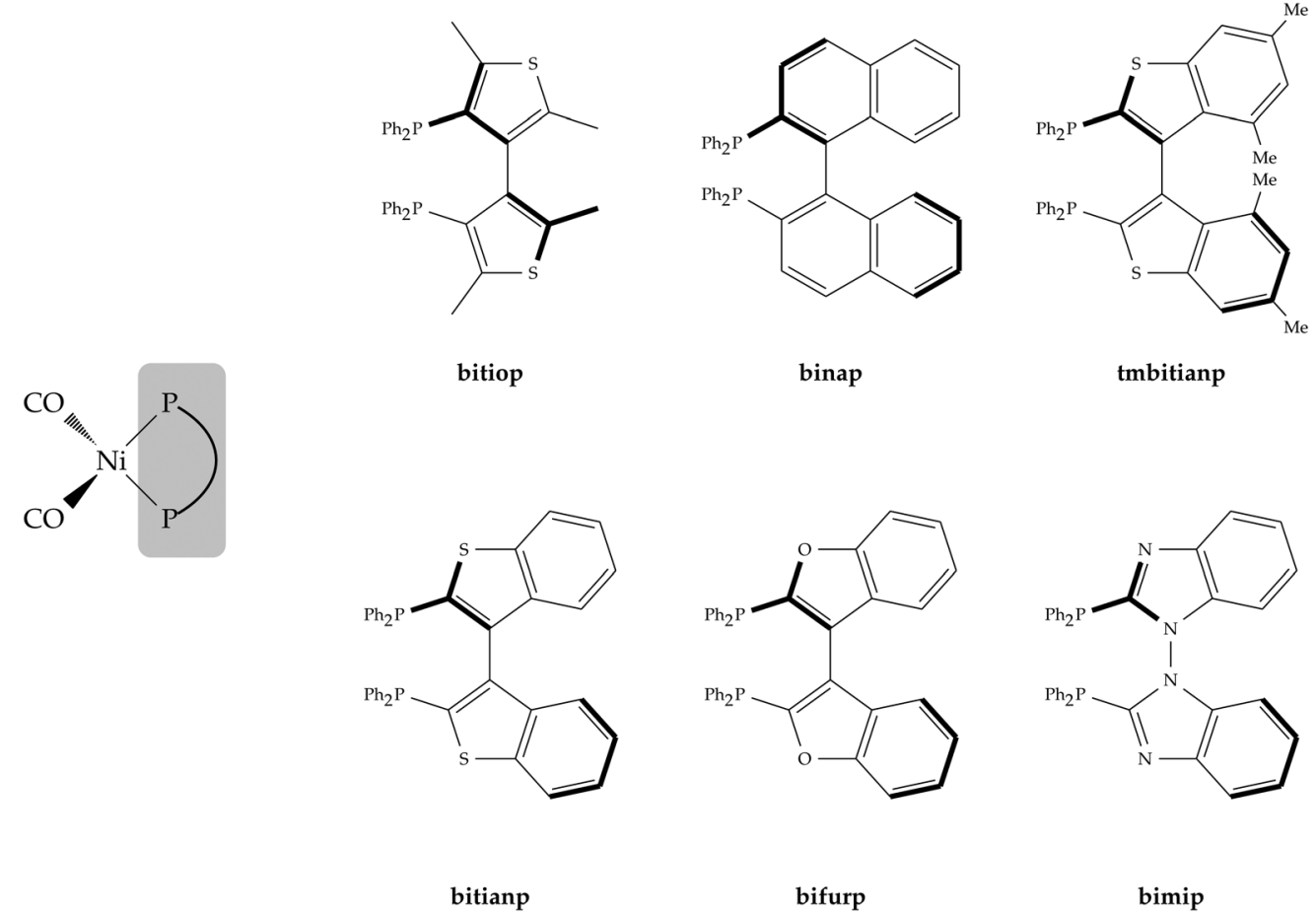

Fig. 1 Chemical structures and abbreviated names for the six chelating diphosphine ligands and nickel dicarbonyl complexes considered in this work. 
distillation under nitrogen before use. Unless otherwise stated, reagents were purchased from commercial sources and used without further purification. Bitiop, tmbitianp, bitianp, bifurp and bimip were synthesized according to procedures reported in the literature. ${ }^{24,27}$

FTIR spectra of chloroform solutions were collected at room temperature by using a Perkin Elmer (MA, USA) FTIR Spectrometer "Spectrum One" in a spectral region between 2200 and $1600 \mathrm{~cm}^{-1}$ and analyzed using the transmittance technique with 32 scans per ion and $4 \mathrm{~cm}^{-1}$ resolution.

${ }^{1} \mathrm{H},{ }^{13} \mathrm{C}$, and ${ }^{31} \mathrm{P}$ NMR spectra were recorded in $\mathrm{CDCl}_{3}$ on a $300 \mathrm{MHz}$ Bruker DRX Avance equipped with a non-reverse probe or a $400 \mathrm{MHz}$ Bruker DRX Avance. Chemical shifts (in ppm) were referenced to a residual solvent proton/carbon peak or using external standard $85 \% \mathrm{H}_{3} \mathrm{PO}_{4}$ for ${ }^{31} \mathrm{P}$ NMR. Signal multiplicity was determined as s (singlet), d (doublet), t (triplet), q (quartet) or m (multiplet).

General procedure for the synthesis of $\mathrm{Ni}$ complexes. The synthesis of the nickel complexes was performed in an NMR tube. To a solution of the diphosphine ligand in $\mathrm{CDCl}_{3}(1 \mathrm{mM})$, one mmol of $\left[\mathrm{Ni}(\mathrm{CO})_{4}\right]$ was added and the resulting solution was stirred. The reaction was then monitored by ${ }^{31} \mathrm{P}$ NMR. The reaction of $\left[\mathrm{Ni}(\mathrm{CO})_{4}\right]$ with the diphosphines quickly produced the corresponding tetrahedral dicarbonyl diphosphine complexes. The rigidity of the biaryl backbone allowed the reaction to proceed at room temperature without the production of side products, as stated by the presence of a single peak in the ${ }^{31} \mathrm{P}\left\{{ }^{1} \mathrm{H}\right\}$ NMR spectra.

[Ni(CO) $)_{2}$ (bitiop)]. ${ }^{1} \mathrm{H}$ NMR (300 $\left.\mathrm{MHz}, \mathrm{CDCl}_{3}, 298 \mathrm{~K}\right) \delta$ : $8.06(\mathrm{~m}, 4 \mathrm{H}), 7.52(\mathrm{~m}, 4 \mathrm{H}), 7.36(\mathrm{~m}, 6 \mathrm{H}), 7.16(\mathrm{~m}, 6 \mathrm{H}), 1.83$ (s, 6H), 1.62 (s, 6H) ppm; ${ }^{31} \mathrm{P}\left\{{ }^{1} \mathrm{H}\right\}$ NMR (121.5 $\mathrm{MHz}, \mathrm{CDCl}_{3}$, $298 \mathrm{~K}) \delta: 29.5$ (s, 2P) ppm; ${ }^{13} \mathrm{C}\left\{{ }^{1} \mathrm{H}\right\}$ NMR (75 $\mathrm{MHz}, \mathrm{CDCl}_{3}$, $298 \mathrm{~K}) \delta: 201.48(\mathrm{~s}), 173.78(\mathrm{~s}), 137.57$ (s), 136.93-134.88 (m), $132.20(\mathrm{~s}), 129.74(\mathrm{~s}), 128.81$ (s), $128.23(\mathrm{~m}), 127.51(\mathrm{~m}), 16.38(\mathrm{~s})$, $14.38(\mathrm{~s}) \mathrm{ppm}$.

$\left[\mathrm{Ni}(\mathrm{CO})_{2}\right.$ (binap)]. ${ }^{1} \mathrm{H} \mathrm{NMR}\left(300 \mathrm{MHz}, \mathrm{CDCl}_{3}, 298 \mathrm{~K}\right) \delta: 8.04$ $(\mathrm{s}, 4 \mathrm{H}), 7.44(\mathrm{~d}, J=6.4 \mathrm{~Hz}, 12 \mathrm{H}), 7.23(\mathrm{~d}, J=7.4 \mathrm{~Hz}, 6 \mathrm{H}), 7.02(\mathrm{~s}$, $2 \mathrm{H}), 6.86(\mathrm{~d}, J=8.1 \mathrm{~Hz}, 2 \mathrm{H}), 6.56(\mathrm{~d}, J=6.0 \mathrm{~Hz}, 2 \mathrm{H}), 6.49(\mathrm{~d}, J=$ 6.2 Hz, 4H) ppm; ${ }^{31} \mathrm{P}\left\{{ }^{1} \mathrm{H}\right\} \mathrm{NMR}\left(121.5 \mathrm{MHz}, \mathrm{CDCl}_{3}, 298 \mathrm{~K}\right) \delta$ : 34.0 (s, 2P) ppm; ${ }^{13} \mathrm{C}\left\{{ }^{1} \mathrm{H}\right\} \mathrm{NMR}\left(75 \mathrm{MHz}, \mathrm{CDCl}_{3}, 298 \mathrm{~K}\right) \delta: 201.48$ (s), 173.78 (s), 136.12-135.14 (m), 133.70 (s), 133.25 (s), 132.40 (s), 130.26 (s), 128.93 (s), 128.51 (s), 128.14 (s), 127.91-127.59 (m), 127.59-127.11 (m), 100.30 (s) ppm.

[Ni(CO) $)_{2}$ (tmbitianp)]. ${ }^{1} \mathrm{H}$ NMR (300 $\left.\mathrm{MHz}, \mathrm{CDCl}_{3}, 298 \mathrm{~K}\right) \delta$ : $8.00(\mathrm{~m}, 3 \mathrm{H}), 7.66-7.54(\mathrm{~m}, 3 \mathrm{H}), 7.46(\mathrm{~m}, 5 \mathrm{H}), 7.25(\mathrm{~m}, 2 \mathrm{H}), 7.10$ $(\mathrm{s}, 2 \mathrm{H}), 6.89-6.72(\mathrm{~m}, 5 \mathrm{H}), 6.56(\mathrm{~s}, 2 \mathrm{H}), 2.29(\mathrm{~s}, 6 \mathrm{H}), 1.67(\mathrm{~s}, 6 \mathrm{H})$ ppm; ${ }^{31} \mathrm{P}\left\{{ }^{1} \mathrm{H}\right\}$ NMR (121.5 MHz, $\left.\mathrm{CDCl}_{3}, 298 \mathrm{~K}\right) \delta: 26.6(\mathrm{~s}, 2 \mathrm{P})$ ppm; ${ }^{13} \mathrm{C}\left\{{ }^{1} \mathrm{H}\right\}$ NMR (75 MHz, $\left.\mathrm{CDCl}_{3}, 298 \mathrm{~K}\right) \delta: 192.00(\mathrm{~s})$, 141.40 (s), 136.44 (s), 135.70 (s), 134.30 (s), 134.61-133.97 (m), 133.63 (s), 133.19 (d, $J=17.0 \mathrm{~Hz}), 132.65$ (dd, $J=24.2,10.2 \mathrm{~Hz}$ ), 131.86 (s), 128.20 (dt, $J=24.1,11.0 \mathrm{~Hz}), 21.59$ (d, $J=18.9 \mathrm{~Hz}$ ), 20.19 (s) ppm.

[Ni(CO) $)_{2}$ (bitianp)]. ${ }^{1} \mathrm{H}$ NMR (300 $\left.\mathrm{MHz}, \mathrm{CDCl}_{3}, 298 \mathrm{~K}\right) \delta$ : $7.87(\mathrm{~m}, 2 \mathrm{H}), 7.74(\mathrm{~m}, 2 \mathrm{H}), 7.66(\mathrm{~m}, 2 \mathrm{H}), 7.50(\mathrm{~m}, 8 \mathrm{H}), 7.29$ (m, 3H), 7.19 (m, 2H), $7.13(\mathrm{~m}, 3 \mathrm{H}), 6.99(\mathrm{~m}, 2 \mathrm{H}), 6.89(\mathrm{~m}, 2 \mathrm{H})$; ${ }^{31} \mathrm{P}\left\{{ }^{1} \mathrm{H}\right\}$ NMR (121.5 MHz, $\left.\mathrm{CDCl}_{3}, 298 \mathrm{~K}\right) \delta: 22.9$ (s, 2P) ppm;
${ }^{13} \mathrm{C}\left\{{ }^{1} \mathrm{H}\right\}$ NMR (75 MHz, $\left.\mathrm{CDCl}_{3}, 298 \mathrm{~K}\right) \delta: 200.10(\mathrm{~s}), 173.84(\mathrm{~s})$, 140.71 (s), 134.17 (s), 133.95 (s), 132.58 (s), 130.43 (s), 129.23 (s), 128.49 (s), 127.75 (s), 124.64 (s), 124.00 (s), 123.53 (s), 121.87 (s), $99.80(\mathrm{~s}) \mathrm{ppm}$.

[Ni(CO) $)_{2}$ (bifurp)]. ${ }^{1} \mathrm{H}$ NMR $\left(300 \mathrm{MHz}, \mathrm{CDCl}_{3}, 298 \mathrm{~K}\right) \delta$ : $7.71-7.58(\mathrm{~m}, 4 \mathrm{H}), 7.52(\mathrm{~d}, J=7.6 \mathrm{~Hz}, 2 \mathrm{H}), 7.46-7.30(\mathrm{~m}$, 14H), 7.29-7.14 (m, 8H) ppm; ${ }^{31} \mathrm{P}\left\{{ }^{1} \mathrm{H}\right\}$ NMR (121.5 MHz, $\mathrm{CDCl}_{3}$, $298 \mathrm{~K}) \delta: 16.0$ (s, 2P) ppm; ${ }^{13} \mathrm{C}\left\{{ }^{1} \mathrm{H}\right\} \mathrm{NMR}\left(75 \mathrm{MHz}, \mathrm{CDCl}_{3}\right.$, $298 \mathrm{~K}) \delta: 198.43(\mathrm{~s}), 192.03(\mathrm{~s}), 156.66(\mathrm{~s}), 135.48(\mathrm{~d}, J=44.4 \mathrm{~Hz})$, $134.78(\mathrm{~d}, J=37.5 \mathrm{~Hz}), 134.09-132.46(\mathrm{~m}), 129.85(\mathrm{~d}, J=$ $20.6 \mathrm{~Hz}$ ), 129.13-127.80 (m), 125.71 (s), 123.21 (s), 121.79 (s), 112.22 (s) ppm.

[Ni(CO) ${ }_{2}$ (bimip)]. ${ }^{1} \mathrm{H}$ NMR (300 MHz, $\left.\mathrm{CDCl}_{3}, 298 \mathrm{~K}\right) \delta: 8.17$ (s, 2H), $7.53(\mathrm{~m}, 12 \mathrm{H}), 7.12(\mathrm{~s}, 2 \mathrm{H}), 6.81(\mathrm{~s}, 10 \mathrm{H}), 6.18(\mathrm{~s}, 2 \mathrm{H})$ ppm; ${ }^{31} \mathrm{P}\left\{{ }^{1} \mathrm{H}\right\}$ NMR (121.5 MHz, $\left.\mathrm{CDCl}_{3}, 298 \mathrm{~K}\right) \delta: 18.4(\mathrm{~s}, 2 \mathrm{P})$ ppm; ${ }^{13} \mathrm{C}\left\{{ }^{1} \mathrm{H}\right\}$ NMR (75 MHz, $\left.\mathrm{CDCl}_{3}, 298 \mathrm{~K}\right) \delta: 198.91$ (s), 192.02 (s), $133.72(\mathrm{~d}, J=28.1 \mathrm{~Hz}), 130.51(\mathrm{~d}, J=21.9 \mathrm{~Hz}), 128.82(\mathrm{~s})$, 124.23 (s), 123.57 (s), 121.01 (s), 109.42 (s) ppm.

\subsection{Computational details}

Geometry optimization. Geometry optimization and frequency calculations were performed using density functional theory (DFT) with the Gaussian suite of programs (G09). ${ }^{32}$ The B3LYP ${ }^{33,34}$ exchange-correlation functional was adopted, in conjunction with the $6-31+G^{*}$ basis set ${ }^{35}$ (see also ref. 36 ). Semiempirical dispersion contributions were also taken into account by inclusion of Grimme's D3BJ ${ }^{37}$ model as implemented in Gaussian. Calculations were performed both in vacuo and by including the bulk solvent effects by means of the polarizable continuum model (PCM $)^{38-40}$ using the integral equation formalism model (IEFPCM) as implemented in Gaussian. ${ }^{41}$

In the absence of crystallographic data, the structure of the complexes was determined as follows. The ligands were built starting form their X-ray structure. ${ }^{24-27}$ They were then coordinated to the tetrahedral $\mathrm{Ni}(\mathrm{CO})_{2}$ fragment and the geometry of the resulting complex was optimized. For each complex, several starting points were tested. Five out of six complexes presented a well-defined minimum with a pseudo $C_{2 \mathrm{v}}$ geometry at the diphosphine back-bone. For the remaining one, namely the bifurp complex, two minima with comparable energy were found. The lowest-energy one (having pseudo $C_{2 \mathrm{v}}$ geometry) is hereafter labeled as bifurp1. The other one (which on the contrary does not show a pseudo $C_{2 \mathrm{v}}$ geometry), is labeled as bifurp2. Vibrational analysis confirmed all structures to be true energy minima.

As expected, in all of the considered complexes the ligands showed similar values of the bite angle, with the maximum difference being below $5^{\circ}$ (see Table S1 in the ESI $\dagger$ ). As mentioned, the bite angle can affect the interaction between the orbitals of the fragments and, in turn, the amount of donation and back-donation between the ligand and the metal. This effect is minimized in our work by the fact that, as just mentioned, all ligands in the considered complexes show a similar bite angle.

Vibrational analysis. As is well known, the inclusion of solvent and anharmonic effects is crucial in order to obtain accurate predictions of vibrational frequencies. 
Anharmonic calculations were performed using the GVPT2 model. ${ }^{42,43}$ Cubic and semi-diagonal quartic force constants were computed by numerical differentiation (with displacements of $0.01 \AA$ ) of the analytical Hessian along each active normal coordinate. In order to reproduce anharmonic effects at a reasonable computational cost, a reduced dimensionality (RD) approach was adopted. ${ }^{44,45}$ In the RD approach, the numerical differentiation is performed only along a subset of modes defined as active, whereas the other modes are treated as harmonic. Reliable results are then obtained if the set of selected active modes is large enough to include all the couplings involved in the frequencies of interest. The carbonyl stretchings are characterized by well-defined and isolated bands, thus it is reasonable to consider only these modes as active in the anharmonic calculations. No significant coupling with other modes has been found.

Using the PCM, the two harmonic carbonyl bands are decreased by about $20 \mathrm{~cm}^{-1}$ with respect to in vacuo calculations. The anharmonic corrections, which as mentioned were obtained at a modest additional computational cost, further red-shifted the bands towards the experimental ones by about $28 \mathrm{~cm}^{-1}$ for all complexes and improved the correlation of the carbonyl stretching frequencies with the ligand-to-metal donation charge transfers (see Fig. S2 in the ESI $\dagger$ and later on in the article). All spectra and coupling matrices were generated and analyzed using the virtual multi-frequency spectrometer Draw (VMS-Draw). ${ }^{46,47}$

Bond analysis. Bond analysis was performed by means of the recently proposed natural orbitals for chemical valence/charge displacement (NOCV/CD) scheme. ${ }^{31}$ The NOCV analysis was performed by interfacing G09 with an ad hoc written program (direct implementation of an NOCV module in the Gaussian program suite is presently being pursued). Charge-displacement analysis on discretized electron densities in the form of Gaussian cube files was carried out using the CUBES program suite. ${ }^{48}$ Integration of the NOCV/CD analysis tools in the CAFFEINE ${ }^{49}$ molecular visualization software for three-dimensional projection of orbitals and densities in an immersive-virtual-reality (IVR) environment is the subject of current work going on in our group and will be discussed extensively in a forthcoming publication.

\section{Results}

\subsection{Carbonyl stretching frequencies and the electronic properties of the ligands: experimental findings}

The observed symmetric and antisymmetric carbonyl stretching frequencies $\left(\nu_{\mathrm{CO}}^{\text {exp }}\right)$ for the six nickel dicarbonyl complexes considered in this work are reported in Table 1 . In the same table, experimental estimates of the basicity $\left(\mathrm{p} K_{\mathrm{a}}\right)$ and electrochemical oxidative potential $\left(E^{0}\right)$ of the free ligands are also given.

In a recent work coauthored by some of the present authors, a good correlation between the $\mathrm{p} K_{\mathrm{a}}$ values of the free ligands

‡ S. Rampino, The WAVERLEY program package, see http://www.srampino.com/ code.html\#Waverley (accessed 4 January 2017).
Table 1 Experimental and calculated properties of the ligands and complexes considered in this work $^{a}$

\begin{tabular}{|c|c|c|c|c|c|c|}
\hline \multirow[b]{2}{*}{ Ligand } & \multirow[b]{2}{*}{$\mathrm{p} K_{\mathrm{a}}$} & \multirow[b]{2}{*}{$E^{0}(\mathrm{~V})$} & \multicolumn{2}{|c|}{$\nu_{\mathrm{CO}}^{\exp }\left(\mathrm{cm}^{-1}\right)$} & \multicolumn{2}{|c|}{$\nu_{\mathrm{CO}}^{\text {calc }}\left(\mathrm{cm}^{-1}\right)$} \\
\hline & & & Sym. & Asym. & Sym. & Asym. \\
\hline bitiop & 3.8 & 0.57 & 1995 & 1933 & 2022 & 1961 \\
\hline binap & 2.9 & 0.63 & 1997 & 1936 & 2025 & 1965 \\
\hline tmbitianp & 1.2 & 0.76 & 2003 & 1944 & 2028 & 1970 \\
\hline bitianp & 1.1 & 0.83 & 2007 & 1947 & 2031 & 1973 \\
\hline bifurp $^{b}$ & -0.1 & 1.03 & 2012 & 1953 & 2036 & 1979 \\
\hline bimip & -1.16 & 1.15 & 2018 & 1961 & 2043 & 1986 \\
\hline
\end{tabular}

${ }^{a}$ Experimental basicity ( $\mathrm{p} K_{\mathrm{a}}$, values from ref. 50$)$ and electrochemical oxidative potential $\left(E^{0}\right.$, values from ref. 27$)$ of the free ligands. Experimental $\left(\nu_{\mathrm{CO}}^{\text {exp }}\right)$ and calculated $(\nu$ calc $)$ symmetric and antisymmetric carbonyl stretching frequencies in the nickel complexes. ${ }^{b}$ Calculated carbonyl stretching frequencies are a weighted average $(0.66: 0.34)$ of the two conformer contributions (see Section 2).

and their oxidation potentials $E^{0}$ has been noted. ${ }^{50}$ Both $E^{0}$ and $\mathrm{p} K_{\mathrm{a}}$ have been, in the past, taken as a measure of the $\sigma$-donor ability of the ligand (see for instance ref. 27 and 51, respectively), though for the latter objections have been raised for ligands which feature high steric hindrance ${ }^{52}$ (which however is not the case of the ligands considered herein).

In Fig. 2 the observed values of the symmetric carbonyl stretching frequency $\left(\nu_{\mathrm{CO}}^{\exp }\right)$ are plotted against the values of $\mathrm{p} K_{\mathrm{a}}$ (top panel) and $E^{0}$ (bottom panel) of the free ligands. Both the plots show a fairly good correlation $\left(R^{2}=0.969\right.$ and 0.988 , respectively), with slightly better results for the correlation of $\nu_{\mathrm{CO}}^{\exp }$ with $E^{0}$. The slightly worse correlation between $\nu_{\mathrm{CO}}^{\exp }$ and $\mathrm{p} K_{\mathrm{a}}$ might be due to the fact that the values of $\mathrm{p} K_{\mathrm{a}}$ might provide a not so accurate description of the basicity of the ligands, since the interaction of their phosphine groups with the hard acid $\mathrm{H}^{+}$differs significantly from that with the soft ones such as transition metals ( $\mathrm{Ni}$ in the case of our complexes).$^{53}$ It is worth noting here that we choose to use the symmetric carbonyl stretching frequencies for consistency with Tolman's approach, although similar results can be obtained using the antisymmetric ones (see Fig. S1 in the ESI $\dagger$ ).

These results, especially in view of the fact that all ligands feature a similar bite angle in the complexes, suggest a close relation between the $\sigma$-donor ability of the chelating diphosphines and the carbonyl stretching frequencies in the related nickel dicarbonyl complexes. In particular, the carbonyl stretching frequencies are more red-shifted due to the greater donor power of the chelating ligand. However, the data discussed so far do not allow us to go beyond these considerations and for a deeper understanding a theoretical analysis is in order.

Before moving to the next section, a comment is due. For the sake of consistency, in the following we will use the calculated $\left(\nu_{\mathrm{CO}}^{\text {calc }}\right)$ carbonyl stretching frequencies rather than the observed $\left(\nu_{\mathrm{CO}}^{\text {exp }}\right)$ ones. The values of $\nu_{\mathrm{CO}}^{\text {calc }}$ are given in the rightmost columns of the already discussed Table 1 and are plotted in Fig. 3 against those of $\nu_{\mathrm{CO}}^{\exp }$.

As evident from the figure, despite a blue shift of $\sim 25 \mathrm{~cm}^{-1}$, a tight correlation $\left(R^{2}=0.988\right)$ is found between the two quantities, which makes them indeed interchangeable in any discussion regarding their trend. 

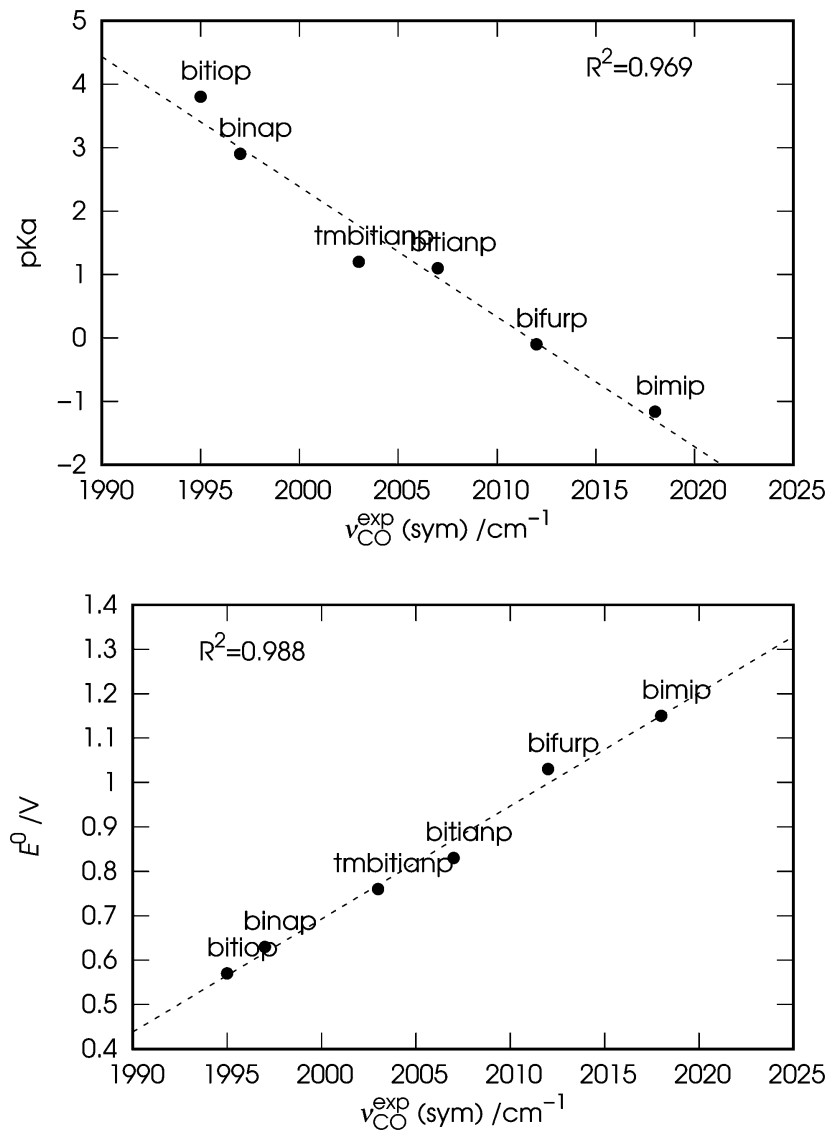

Fig. 2 Correlation between the experimental symmetric carbonyl stretching frequencies ( $\left.\nu_{\mathrm{CO}}^{\text {exp }}\right)$ of the nickel dicarbonyl complexes with the six considered ligands, and the experimental (i) basicity ( $\mathrm{p} K_{\mathrm{a}}$, top panel) and (ii) electrochemical oxidative potential $\left(E^{0}\right.$, bottom panel) of the free ligands (see Table 1).

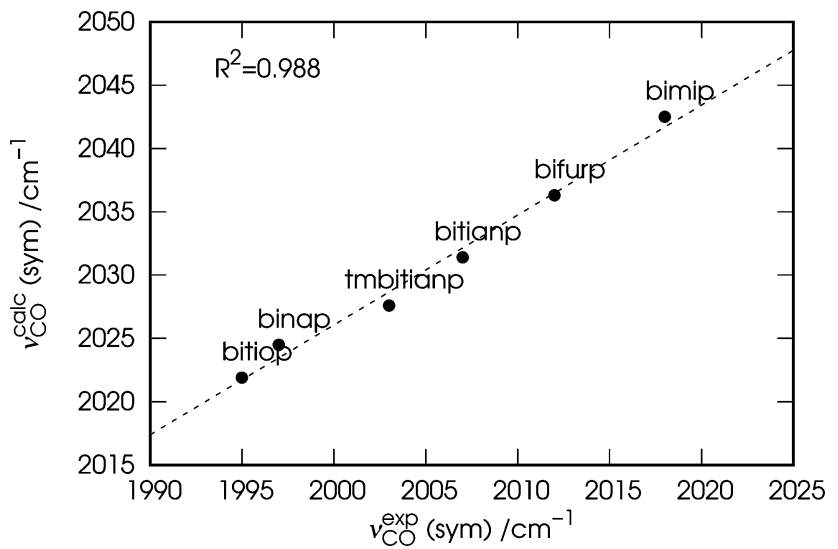

Fig. 3 Correlation between the experimental $\left(\nu_{C}^{\exp }\right)$ and calculated carbonyl stretching frequencies ( $\nu_{\mathrm{CO}}^{\mathrm{calc}}$ ) of the nickel dicarbonyl complexes with the six considered ligands.

\subsection{The metal-ligand chemical bond: insights from theory}

As mentioned above, in order to investigate the relation between the stretching frequencies of carbonyls and the metal-ligand bonding properties in the set of considered complexes, we made use of the NOCV/CD analysis scheme developed by one of us in collaboration with others. ${ }^{31}$ While such scheme has been described in detail in ref. 31, we briefly review here its foundations for a clearer reading of the forthcoming discussion.

Within NOCV theory, given an adduct $\mathrm{AB}$ formed by fragments $\mathrm{A}$ and $\mathrm{B}$, the electron charge rearrangement taking place after the formation of the A-B bond is formulated as the difference $\Delta \rho$ between the total electron density of the adduct and a reference electron density associated with the unbound fragments A and B (where all densities are worked out from singledeterminant wavefunctions). This last quantity is constructed from the occupied molecular orbitals of the two isolated fragments (computed using for each fragment the geometry that it has in the adduct), after the same orbitals have been made orthonormal to each other. ${ }^{54-56}$ Then, by diagonalising the so-called 'valence operator' (for which the reader is referred to Nalewajski and Mrozek's valence theory) ${ }^{57-59}$ and finding its eigenvalues $v_{k}$ and eigenfunctions $\varphi_{k}$ (termed 'natural orbitals for chemical valence', NOCVs), $\Delta \rho$ can be decomposed into weighed contributions ascribable to pairs of NOCVs coupled by eigenvalue $v_{k}^{60}$

$$
\Delta \rho=\sum_{k} v_{k}\left(\left|\varphi_{k}\right|^{2}-\left|\varphi_{-k}\right|^{2}\right)=\sum_{k} v_{k} \Delta \rho_{k} .
$$

In other words, the total electron charge rearrangement taking place after bond formation results from additive charge flows of $v_{k}$ electrons flowing from orbital $\varphi_{-k}$ to orbital $\varphi_{k}$, with $k$ running over twice the number of occupied molecular orbitals of the adduct. It is worth mentioning here that formalisms have been developed to associate with each of these charge-flow components an energy-contribution term to the overall interaction energy. The reader is referred to the pioneering work of Ziegler ${ }^{56}$ and Frenking ${ }^{61}$ for further details on this subject.

Typically, only a few NOCV components in eqn (1) have a significant weight and thus contribute significantly to the overall charge rearrangement, while the remaining components contribute to a negligible extent due to very small-valued weights. Often, a qualitative visual inspection of the few important contributions to the overall charge rearrangement reveals that these have a clear chemical meaning, such as donation and back-donation charge flows, providing a powerful means of understanding the detailed features of the analyzed chemical bond.

To show how this works on a real case, we take the nickel dicarbonyl complex with the ligand bitiop and discuss in detail the results of the related NOCV analysis. In this case, the adduct is the whole $\left[\mathrm{Ni}(\mathrm{CO})_{2}(\right.$ bitiop)] complex at its optimised geometry, and fragments are defined as (i) the $\mathrm{Ni}(\mathrm{CO})_{2}$ moiety and (ii) the bitiop moiety, both frozen at their in-adduct geometries. The largest twelve NOCV eigenvalues $v_{k}$ for this complex are listed in descending order in the second column of Table 2 .

As these data suggest, the overall charge rearrangement following bond formation between the ligand and the metallic moiety results mainly from two components each involving a charge flow of about $0.6 e$, and four components each involving a charge flow of about $0.3 \mathrm{e}$. With the exception of the 7-th component $\left(v_{7}=0.17 e\right.$, on which we shall briefly return when 
Table 2 Weights (NOCV eigenvalues $v_{k}$ ) of the first twelve components of the charge rearrangement following metal-ligand bond formation in the nickel dicarbonyl complexes

\begin{tabular}{llllllll}
\hline & bitiop & binap & tmbitianp & bitianp & bifurp1 & bifurp2 & bimip \\
\hline$v_{1}$ & 0.57 & 0.57 & 0.60 & 0.57 & 0.58 & 0.62 & 0.59 \\
$v_{2}$ & 0.56 & 0.55 & 0.55 & 0.54 & 0.54 & 0.53 & 0.53 \\
$v_{3}$ & 0.32 & 0.34 & 0.34 & 0.34 & 0.35 & 0.33 & 0.35 \\
$v_{4}$ & 0.31 & 0.31 & 0.33 & 0.32 & 0.33 & 0.32 & 0.34 \\
$v_{5}$ & 0.29 & 0.30 & 0.31 & 0.30 & 0.31 & 0.31 & 0.32 \\
$v_{6}$ & 0.27 & 0.26 & 0.26 & 0.26 & 0.27 & 0.27 & 0.27 \\
$v_{7}$ & 0.17 & 0.16 & 0.18 & 0.17 & 0.17 & 0.17 & 0.16 \\
$v_{8}$ & 0.06 & 0.06 & 0.07 & 0.06 & 0.06 & 0.06 & 0.06 \\
$v_{9}$ & 0.06 & 0.06 & 0.06 & 0.06 & 0.06 & 0.06 & 0.06 \\
$v_{10}$ & 0.06 & 0.05 & 0.06 & 0.05 & 0.05 & 0.06 & 0.05 \\
$v_{11}$ & 0.05 & 0.05 & 0.05 & 0.05 & 0.05 & 0.05 & 0.05 \\
$v_{12}$ & 0.05 & 0.05 & 0.04 & 0.05 & 0.05 & 0.05 & 0.04 \\
\hline
\end{tabular}

commenting on Fig. 5), all remaining NOCV pairs are seen to contribute negligibly to the overall charge rearrangement $\left(v_{k} \leq 0.06 e\right)$.

As mentioned, a visual inspection of the NOCV orbital pairs and the associated charge rearrangement can provide chemical insights into the bonding between the analyzed fragments. The first six NOCV orbital pairs $\left(\varphi_{-k}, \varphi_{k}\right)$ and the associated electron charge rearrangement $\Delta \rho_{k}$ for the bitiop complex are shown in Fig. 4 as isodensity surfaces.

Focusing on the first component, following the metal-ligand bond formation a fraction of electrons equal to $v_{1}=0.57 e$ is seen to flow from orbital $\varphi_{-1}$ (clearly depicting the phosphorus in-phase lone-pair orbitals and the $\mathrm{d}_{y^{2}}$ orbital of nickel) to orbital $\varphi_{1}$, which displays probability density in the chelation area (see the related charge flow in the $\Delta \rho_{1}$ plot, with red lobes indicating electron depletion and blue lobes indicating electron accumulation). Analogously, the second NOCV pair describes the charge flow of $0.56 e$ from the phosphorus lone pairs and the $\mathrm{d}_{y z}$ orbital of nickel (both represented by $\varphi_{-2}$ ) to a molecular orbital $\varphi_{2}$ which displays amplitude on the outer shell of the metal and on the LUMOs of the carbonyls. The associated $\Delta \rho_{2}$ plot shows that this component describes a ligand-to-metal donation charge flow. Similarly, a visual inspection of the remaining four components displayed in Fig. 4 (which, as mentioned, contribute to the overall charge rearrangement with half the weight of the first two components), shows that, though less distinctively, components from 3 to 5 can be connected with metal-to-ligand back-donation charge flows while component 6 depicts charge accumulation in-between each Ni-P bond.

The considerations made so far can be summarised as follows. The NOCV analysis conducted on the nickel dicarbonyl complex with bitiop has shown that:

(1) the overall charge rearrangement taking place after the formation of the metal-ligand bond results from a few contributions which can be given a clear chemical meaning;

(2) the first two contributions can be identified as ligand-tometal donation from the phosphorus lone pairs towards the chelation area and the metallic fragment (with electron charge flowing far into the carbonyl regions and populating the $\mathrm{CO}$ anti-bonding LUMOs);

(3) the next four components are associated with charge flows from the metallic fragment to the ligand having $\pi$ symmetry with respect to each metal-phosphorus bond axis, and with charge accumulation between each Ni-P pair.

Though for the sake of conciseness we do not report here them in full, a visual inspection of the NOCV pairs for the six remaining complexes and an analysis of the data in columns 3-8 of Table 2 show that the three conclusions drawn above for the bitiop complex hold for the other complexes too, with differences that are difficult to interpret through the analysis of the isovalued surfaces. Moreover, caution should be used in taking the values of the eigenvalues $v_{k}$ for a comparison between the complexes. Whereas, in fact, the NOCV eigenvalues provide a measure of the charge flowing between NOCV orbital pairs, this can hardly be taken as an estimation of the charge transfer between fragments as NOCV eigenvalues also include intra-fragment charge rearrangement. ${ }^{31}$ That's where charge-displacement $(\mathrm{CD})$ analysis comes into play.

The CD scheme is based on the so-called CD function, ${ }^{62}$ providing a clear and quantitative picture of the charge flow along a selected direction in space, taking place after bond formation. ${ }^{63,64}$ In particular, the CD function is defined as a progressive partial integration along a suitable axis $z$ of an electron density difference $\Delta \rho\left(x, y, z^{\prime}\right)$

$$
\Delta q(z)=\int_{-\infty}^{z} \mathrm{~d} z^{\prime} \int_{-\infty}^{\infty} \int_{-\infty}^{\infty} \Delta \rho\left(x, y, z^{\prime}\right) \mathrm{d} x \mathrm{~d} y
$$

The $z$ axis is usually chosen to be the bond axis between the fragments. Accordingly, the $\mathrm{CD}$ function at a given point $z$ quantifies the exact amount of electron charge that, upon formation of the bond, is transferred from right to left (the direction of decreasing $z$ ) across a plane perpendicular to the bond axis through $z$. Negative values of the $\mathrm{CD}$ function identify charge flow in the opposite direction. It is worth recalling here that NOCV/CD analysis is here for the first time extended to the case of chelation bonds. Accordingly, to the purpose of assessing the charge transfer between the metallic moiety and the ligand, we choose the $z$ axis as the line bisecting the $(\mathrm{CO}) \widehat{\mathrm{Ni}}(\mathrm{CO})$ angle and lying on the $\mathrm{Ni}(\mathrm{CO})_{2}$ plane.

The $\mathrm{CD}$ curves related to the first six components of the charge rearrangement following the metal-ligand bond formation in the bitiop complex are displayed in Fig. 5.

The CD curves for components from 7 to 12 are also shown as gray lines. We recall here that the value of the $\mathrm{CD}$ function at a given point $z$ represents the exact amount of electron charge that, upon bond formation, has flown from right to left through a plane perpendicular to the $z$ axis through point $z$. Negative values of the $\mathrm{CD}$ function represent charge flow in the opposite direction (from left to right).

The modest entity of the CD curves displayed in gray color confirms that the overall charge rearrangement along the interaction axis upon the metal-ligand bond formation is almost completely recovered by the first six NOCV components, despite the fact that the value of $v_{7}$ seemed to be non-negligible compared to the successive $v_{k}$ values. One of these $(k=2$, light red) is positive throughout the considered $z$ segment and thus represents charge flow in the metal $\leftarrow$ ligand direction throughout the molecular region. For example, the charge transferred from the ligand region to the metallic fragment through the plane orthogonal 

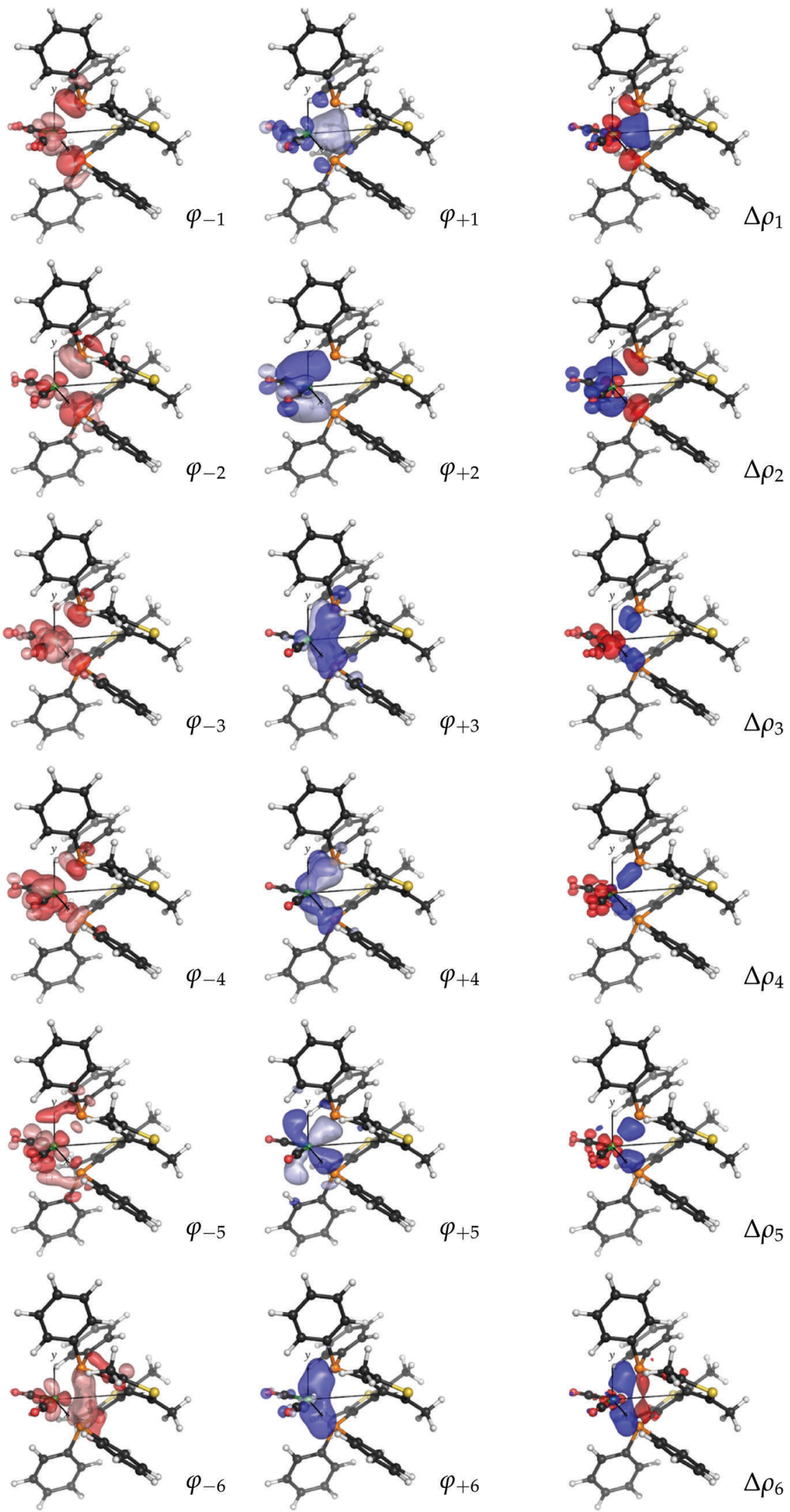

Fig. 4 NOCV pairs $\left(\varphi_{-k}\right.$ and $\varphi_{k}$, isodensity surfaces at $\left.\pm 0.05\left(e \text { Bohr }^{-3}\right)^{1 / 2}\right)$ and associated charge rearrangement $\left(\Delta \rho_{k}\right.$, isodensity surfaces at \pm 0.005 e Bohr $\left.{ }^{-3}\right)$ taking place after the metal-ligand bond formation in the nickel dicarbonyl complex with the ligand bitiop. In $\Delta \rho_{k}$ plots, red isosurfaces represent regions of electron depletion, blue isosurfaces represent regions of electron accumulation. 


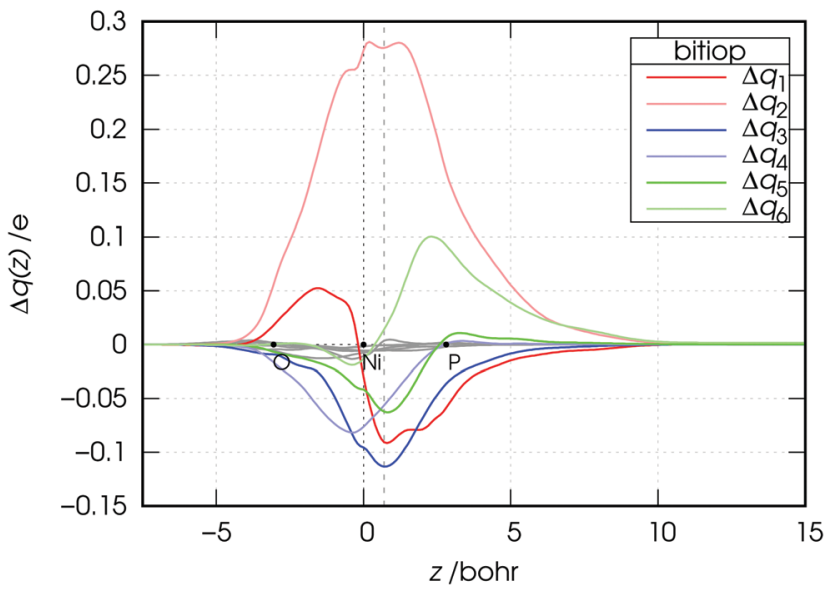

Fig. 5 Charge-displacement curves $\Delta q(z)$ for the $\left[\mathrm{Ni}(\mathrm{CO})_{2}(\right.$ bitiop $\left.)\right]$ complex associated with the first six NOCV components of $\Delta \rho$. Note that the curves associated with NOCV components from 7 to 12 are also displayed as gray lines.

to the $z$ axis at $z=0.7 \mathrm{Bohr}$ (dashed vertical line) due to component 2 amounts exactly to $0.275 e$. Analogously, component 3 (blue curve) depicts charge flux in the metal $\rightarrow$ ligand direction throughout the molecular region, indicating a charge transfer of $-0.113 e$ (i.e. $0.113 e$ in the direction from left to right) through the surface identified by the dashed vertical line. For illustrative purposes, the values of all charge transfers (CTs) through this surface are listed in Table 3 for the first twelve NOCV components and all the considered complexes.

We note now that both components 1 and 2 describe charge flowing from the phosphorus lone-pair orbitals of the ligands (taken either in-phase: component 1, or out-of-phase: component 2) and should be considered together from a chemical point of view. In Fig. 6 the CD curve related to the sum of these two components is reported.

As the figure shows, the overall flux associated with the charge flowing from the lone pairs of the ligands results in a donation flux throughout the whole molecular region and displays a minimum at $z=0.7$ Bohr. Moreover, inspection of Fig. 6 shows that there exists a volume region between orthogonal planes to $z$

Table 3 Charge-transfer values $\left(\mathrm{CT}_{k}\right)$ across a dividing plane orthogonal to $z$ through $z=0.7$ Bohr associated with the first twelve NOCV components of the charge rearrangement taking place after metal-ligand bond formation in the nickel dicarbonyl complexes

\begin{tabular}{lrrrrrrr}
\hline & bitiop & binap & tmbitianp & bitianp & bifurp1 & bifurp2 & bimip \\
\hline $\mathrm{CT}_{1}$ & -0.091 & -0.021 & -0.083 & -0.090 & -0.097 & -0.101 & -0.117 \\
$\mathrm{CT}_{2}$ & 0.275 & 0.198 & 0.255 & 0.254 & 0.246 & 0.239 & 0.245 \\
$\mathrm{CT}_{3}$ & -0.113 & -0.117 & -0.118 & -0.120 & -0.124 & -0.092 & -0.127 \\
$\mathrm{CT}_{4}$ & -0.056 & -0.058 & -0.063 & -0.060 & -0.062 & -0.066 & -0.065 \\
$\mathrm{CT}_{5}$ & -0.062 & -0.067 & -0.074 & -0.069 & -0.076 & -0.072 & -0.075 \\
$\mathrm{CT}_{6}$ & 0.014 & 0.007 & 0.012 & 0.009 & 0.006 & 0.017 & 0.007 \\
$\mathrm{CT}_{7}$ & 0.003 & 0.007 & 0.008 & 0.009 & 0.011 & 0.007 & 0.014 \\
$\mathrm{CT}_{8}$ & -0.006 & -0.004 & -0.006 & -0.002 & -0.005 & -0.003 & 0.001 \\
$\mathrm{CT}_{9}$ & -0.005 & -0.002 & -0.002 & -0.005 & 0.001 & -0.000 & -0.005 \\
$\mathrm{CT}_{10}$ & -0.001 & -0.002 & -0.001 & 0.000 & -0.000 & 0.001 & 0.001 \\
$\mathrm{CT}_{11}$ & -0.004 & 0.000 & -0.001 & -0.002 & -0.001 & -0.003 & -0.001 \\
$\mathrm{CT}_{12}$ & -0.001 & -0.001 & -0.000 & 0.001 & 0.001 & -0.000 & 0.001
\end{tabular}

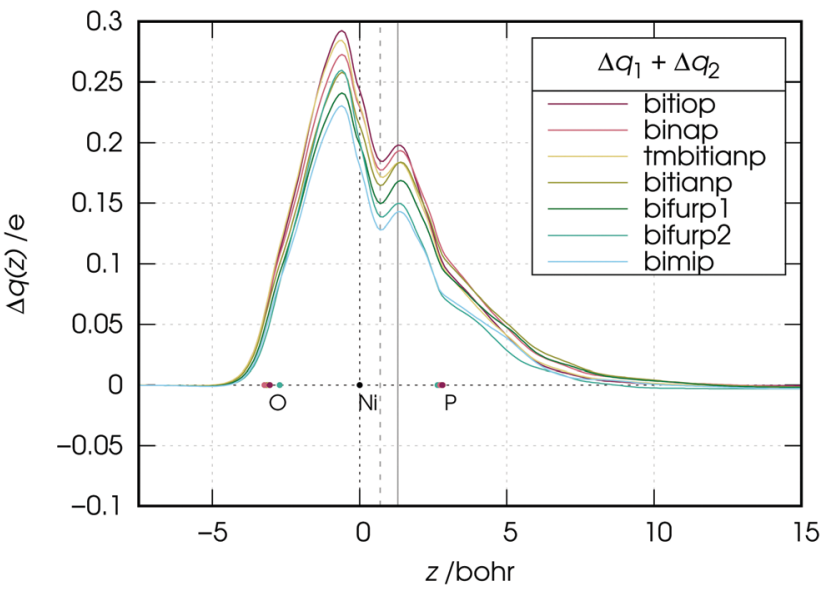

Fig. 6 Charge-displacement curves $\Delta q(z)$ associated with the sum of the first two NOCV components (charge flowing from the phosphorus lone pairs of the ligands) in the nickel dicarbonyl complexes with the considered ligands. Vertical lines at $z=0.7$ and $1.3 \mathrm{Bohr}$ have been used to take quantitative estimates of the ligand-to-metal charge transfers (see text for discussion).

through $z \simeq 0.5$ and $z \simeq 1.3$ Bohr (i.e., in the bond region between $\mathrm{Ni}$ and $\mathrm{P}$ ) where the extent of the charge flowing from right to left (i.e., donated from the phosphorus lone pairs of the ligands to the metal) as a function of the ligand reflects the order of the carbonyl stretching frequencies in the related complexes. This feature, as clearly shown by Fig. 7, is never observed in the curves related to components 3-6, which moreover display no big variation on going from complex to complex (neither their combination, though not shown here, does).

An exception seems to appear in the plot of the NOCV component 3 . In this plot, the curve of the bifurp2 complex is, in fact, markedly higher than those of the other complexes. This is certainly due to the fact that, as mentioned in Section 2, bifurp2 has a different geometry from all other complexes, which evidently decreases the amount of metal-to-ligand back-donation.

Now, as mentioned above, the CD curves depicting the charge flow associated with charge depletion from the lone pairs of the ligands (i.e., the sum of components 1 and 2), reflect over a relatively wide segment of $z$ localized in the metal-ligand bond region the same order that the observed carbonyl stretching frequencies have in the series of the considered complexes. This confirms the hypothesis made in Section 3.1 on the basis of experimental data that there is a correlation between donation from the lone pairs and the red-shift response of the carbonyl stretching frequencies in the complexes. To put this on a quantitative ground we plot in Fig. 8 the associated charge transfer $\mathrm{CT}_{\mathrm{don}}=\mathrm{CT}_{1}+\mathrm{CT}_{2}$ taken at $z=0.7 \mathrm{Bohr}$, against the carbonyl stretching frequencies for the considered complexes.

The figure shows that indeed there is a tight correlation between the two quantities with $R^{2}=0.988$. The correlation remains high also at the boundaries of the mentioned $z$ segment, yielding $R^{2}=0.986$ if CTs are taken at $z=0.5 \mathrm{Bohr}$ and $R^{2}=0.965$ if CTs are taken at $z=1.3 \mathrm{Bohr}$. The fact that bifurp2, with its peculiar geometry and lower amount of metal-to-ligand back-donation, perfectly fits this trend cannot but confirm 

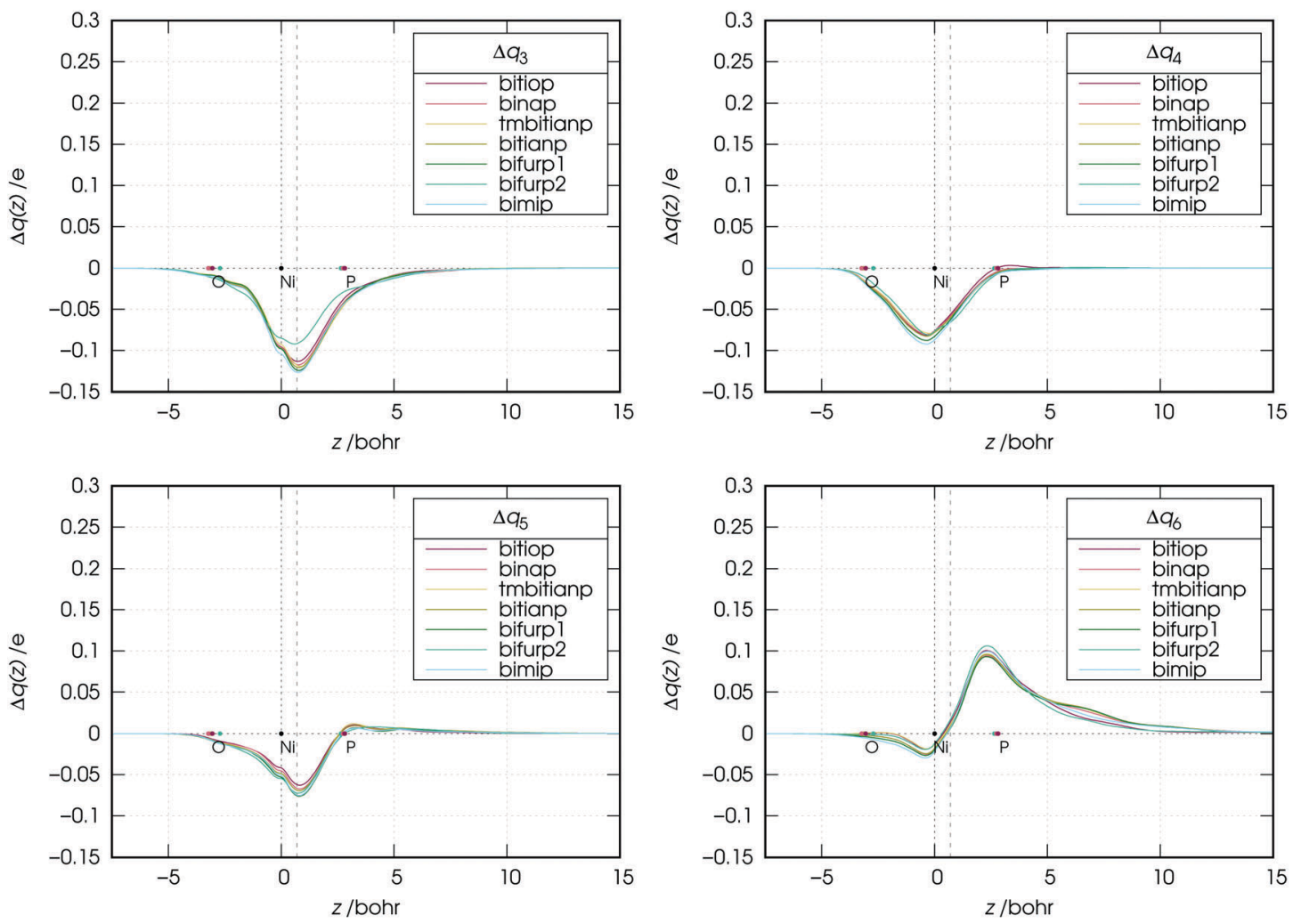

Fig. 7 Charge-displacement curves $(\Delta q(z))$ associated with the $k$-th $(k=3,4,5,6)$ NOCV component in the nickel dicarbonyl complexes with the considered ligands.

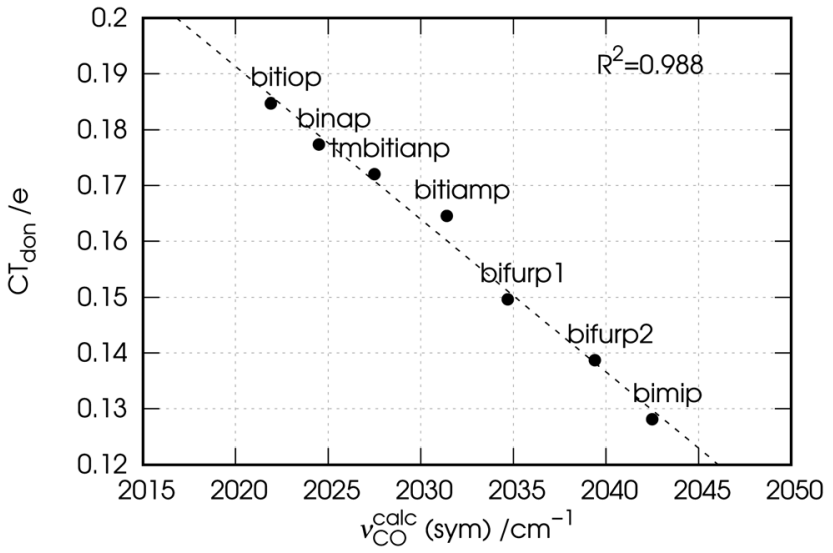

Fig. 8 Correlation between the calculated carbonyl stretching frequencies $(\nu \mathrm{CO})$ and the charge transfer $\left(\mathrm{CT}_{\text {don }}=\mathrm{CT}_{1}+\mathrm{CT}_{2}\right)$ associated with the ligandto-metal donation from the phosphorus lone pairs.

that in the set of the considered complexes it is solely the ligand-to-metal $\sigma$-donation that the carbonyl stretching frequencies respond to.

\section{Conclusions}

In this paper we addressed the issue of the relation between spectroscopic observables and the detailed metal-ligand bonding features in coordination complexes from the original perspective of chelation bonds.

A set of six nickel dicarbonyl complexes with chelating diphosphine ligands were synthesized and experimentally characterized, and a preliminary analysis of the experimental data showed that the observed carbonyl stretching frequencies in the complexes are in good correlation with the electronic properties of the ligands, such as basicity $\left(R^{2}=0.969\right)$ and electrochemical oxidative potentials $\left(R^{2}=0.988\right)$, which can be taken as an estimate of their $\sigma$-donor power. This prompted us to perform a thorough theoretical investigation for a deeper understanding of the features of the metal-ligand chemical bond in the considered complexes. To this purpose the recently proposed natural orbitals for the chemical valence/charge displacement (NOCV/CD) approach was adopted and here for the first time extended to the analysis of chelation bonds. The NOCV/CD analysis of the charge rearrangement taking place upon the metal-ligand bond formation computed by means of density functional theory (DFT), allowed us to single out on a quantitative basis the main components of the metal-ligand interaction in terms of charge flows between the molecular orbitals of the fragments.

We first analyzed in-depth the metal-ligand bonding features for one of the considered complexes, namely that with bitiop. The results showed that the metal-ligand bond formation involves mainly charge flows from the phosphorus lone pairs of the ligands towards both the chelation area and the metallic fragment, with partial charge flowing far into the carbonyl region. The remaining 
charge-rearrangement components involve mainly metal-to-ligand back-donation and charge accumulation between each Ni-P pair. The analysis of the remaining complexes showed that this picture holds for all complexes considered in this work. Then we carried out a cross-comparison on quantitative grounds of the results obtained for the other complexes and showed that it is the bond component associated with charge flowing from the lone pairs of the ligands that quantitatively drives the response of the carbonyl stretching frequencies to the metal-ligand bond formation, with these latter tightly correlating $\left(R^{2}=0.988\right)$ with the metal-to-ligand charge-transfer estimates.

The present results, achieved by both experiment and stateof-the-art theoretical/computational methods, on one hand indicate a method of quantitatively assessing the donor power of chelating ligands in homogeneous catalysis from simple experimental measurements-thus providing a useful tool for designing and predicting the efficiency of new catalysts. On the other hand, they shed light on the nature of chelation bonds themselves confirming the robustness of the NOCV/CD analysis scheme and opening the way to promising future investigations in the field of coordination chemistry, such as accounting for ligands featuring different bite angles in order to quantitatively assess the bite-angle effect on the electronic properties at the metal center.

\section{Acknowledgements}

The research leading to these results has received funding from the European Research Council under the European Union's Seventh Framework Programme (FP/2007-2013)/ERC Grant Agreement no. [320951].

\section{References}

1 P. C. Kamer and P. W. van Leeuwen, Phosphorus(III) ligands in homogeneous catalysis: design and synthesis, John Wiley \& Sons, 2012.

2 C. A. Tolman, J. Am. Chem. Soc., 1970, 92, 2953-2956.

3 C. A. Tolman, Chem. Rev., 1977, 77, 313-348.

4 G. Herzberg, Molecular spectra and molecular structure, Read Books Ltd, 1950, vol. 1.

5 L. J. Bellamy, Carbonyl Frequencies, Springer Netherlands, Dordrecht, 1980, pp. 128-194.

6 D. A. Valyaev, R. Brousses, N. Lugan, I. Fernández and M. A. Sierra, Chem. - Eur. J., 2011, 17, 6602-6605.

7 D. Setiawan, R. Kalescky, E. Kraka and D. Cremer, Inorg. Chem., 2016, 55, 2332-2344.

8 M. Alcarazo, Acc. Chem. Res., 2016, 49, 1797-1805.

9 A. W. Ehlers, S. Dapprich, S. F. Vyboishchikov and G. Frenking, Organometallics, 1996, 15, 105-117.

10 C. Massera and G. Frenking, Organometallics, 2003, 22, 2758-2765.

11 T. Leyssens, D. Peeters, A. G. Orpen and J. N. Harvey, Organometallics, 2007, 26, 2637-2645.

12 R. Tonner and G. Frenking, Organometallics, 2009, 28, 3901-3905.
13 V. Tognetti, L. Joubert, P. Cortona and C. Adamo, J. Phys. Chem. A, 2009, 113, 12322-12327.

14 P. Dierkes and P. W. N. M. van Leeuwen, J. Chem. Soc., Dalton Trans., 1999, 1519-1530.

15 Z. Freixa and P. W. N. M. van Leeuwen, Dalton Trans., 2003, 1890-1901.

16 N. Fey, Dalton Trans., 2010, 39, 296-310.

17 N. Fey, J. N. Harvey, G. C. Lloyd-Jones, P. Murray, A. G. Orpen, R. Osborne and M. Purdie, Organometallics, 2008, 27, 1372-1383.

18 J. Jover, N. Fey, J. N. Harvey, G. C. Lloyd-Jones, A. G. Orpen, G. J. J. Owen-Smith, P. Murray, D. R. J. Hose, R. Osborne and M. Purdie, Organometallics, 2012, 31, 5302-5306.

19 J. Jover and N. Fey, Dalton Trans., 2013, 42, 172-181.

20 C. Flener Lovitt, G. Frenking and G. S. Girolami, Organometallics, 2012, 31, 4122-4132.

21 C. M. Donahue, S. P. McCollom, C. M. Forrest, A. V. Blake, B. J. Bellott, J. M. Keith and S. R. Daly, Inorg. Chem., 2015, 54, 5646-5659.

22 G. A. Ardizzoia, M. Bea, S. Brenna and B. Therrien, Eur. J. Inorg. Chem., 2016, 3829-3837.

23 Y. Canac and C. Lepetit, Inorg. Chem., 2017, 56, 667-675.

24 T. Benincori, E. Brenna, F. Sannicolò, L. Trimarco, P. Antognazza, E. Cesarotti, F. Demartin and T. Pilati, J. Org. Chem., 1996, 61, 6244-6251.

25 T. Benincori, E. Cesarotti, O. Piccolo and F. Sannicolò, J. Org. Chem., 2000, 65, 2043-2047.

26 T. Benincori, E. Brenna, F. Sannicolò, L. Trimarco, P. Antognazza, E. Cesarotti, F. Demartin, T. Pilati and G. Zotti, J. Organomet. Chem., 1997, 529, 445-453.

27 T. Benincori, O. Piccolo, S. Rizzo and F. Sannicolò, J. Org. Chem., 2000, 65, 8340-8347.

28 H. Doucet, T. Ohkuma, K. Murata, T. Yokozawa, M. Kozawa, E. Katayama, A. F. England, T. Ikariya and R. Noyori, Angew. Chem., 1998, 110, 1792-1796.

29 L. Qiu, F. Y. Kwong, J. Wu, W. H. Lam, S. Chan, W.-Y. Yu, Y.-M. Li, R. Guo, Z. Zhou and A. S. C. Chan, J. Am. Chem. Soc., 2006, 128, 5955-5965.

30 I. Rimoldi, E. Cesarotti, D. Zerla, F. Molinari, D. Albanese, C. Castellano and R. Gandolfi, Tetrahedron: Asymmetry, 2011, 22, 597-602.

31 G. Bistoni, S. Rampino, F. Tarantelli and L. Belpassi, J. Chem. Phys., 2015, 142, 084112.

32 M. J. Frisch, G. W. Trucks, H. B. Schlegel, G. E. Scuseria, M. A. Robb, J. R. Cheeseman, G. Scalmani, V. Barone, B. Mennucci, G. A. Petersson, H. Nakatsuji, M. Caricato, X. Li, H. P. Hratchian, A. F. Izmaylov, J. Bloino, G. Zheng, J. L. Sonnenberg, M. Hada, M. Ehara, K. Toyota, R. Fukuda, J. Hasegawa, M. Ishida, T. Nakajima, Y. Honda, O. Kitao, H. Nakai, T. Vreven, J. A. Montgomery Jr, J. E. Peralta, F. Ogliaro, M. Bearpark, J. J. Heyd, E. Brothers, K. N. Kudin, V. N. Staroverov, R. Kobayashi, J. Normand, K. Raghavachari, A. Rendell, J. C. Burant, S. S. Iyengar, J. Tomasi, M. Cossi, N. Rega, J. M. Millam, M. Klene, J. E. Knox, J. B. Cross, V. Bakken, C. Adamo, J. Jaramillo, R. Gomperts, R. E. Stratmann, O. Yazyev, A. J. Austin, R. Cammi, C. Pomelli, J. W. Ochterski, R. L. Martin, K. Morokuma, V. G. Zakrzewski, 
G. A. Voth, P. Salvador, J. J. Dannenberg, S. Dapprich, A. D. Daniels, Ö. Farkas, J. B. Foresman, J. V. Ortiz, J. Cioslowski and D. J. Fox, Gaussian 09 Revision E.01, Gaussian Inc., Wallingford CT, 2009.

33 C. Lee, W. Yang and R. G. Parr, Phys. Rev. B: Condens. Matter Mater. Phys., 1988, 37, 785-789.

34 A. D. Becke, J. Chem. Phys., 1993, 98, 5648-5652.

35 V. A. Rassolov, M. A. Ratner, J. A. Pople, P. C. Redfern and L. A. Curtiss, J. Comput. Chem., 2001, 22, 976-984.

36 H. Kvapilová, A. Vlček, V. Barone, M. Biczysko and S. Záliš, J. Phys. Chem. A, 2015, 119, 10137-10146.

37 S. Grimme, S. Ehrlich and L. Goerigk, J. Comput. Chem., 2011, 32, 1456-1465.

38 V. Barone, M. Cossi and J. Tomasi, J. Chem. Phys., 1997, 107, 3210-3221.

39 M. Cossi, G. Scalmani, N. Rega and V. Barone, J. Chem. Phys., 2002, 117, 43-54.

40 J. Tomasi, B. Mennucci and R. Cammi, Chem. Rev., 2005, 105, 2999-3094.

41 G. Scalmani and M. J. Frisch, J. Chem. Phys., 2010, 132, 114110. 42 V. Barone, J. Chem. Phys., 2005, 122, 014108.

43 J. Bloino and V. Barone, J. Chem. Phys., 2012, 136, 124108.

44 V. Barone, M. Biczysko, J. Bloino, M. Borkowska-Panek, I. Carnimeo and P. Panek, Int. J. Quantum Chem., 2012, 112, 2185-2200.

45 V. Barone, M. Biczysko and J. Bloino, Phys. Chem. Chem. Phys., 2014, 16, 1759-1787.

46 V. Barone, Wiley Interdiscip. Rev.: Comput. Mol. Sci., 2016, 6, 86-110.

47 D. Licari, A. Baiardi, M. Biczysko, F. Egidi, C. Latouche and V. Barone, J. Comput. Chem., 2015, 36, 321-334.

48 S. Rampino, VIRT\&L-COMM, 2015, 7, 6.
49 A. Salvadori, G. Del Frate, M. Pagliai, G. Mancini and V. Barone, Int. J. Quantum Chem., 2016, 116, 1731-1746.

50 G. Facchetti, E. Cesarotti, M. Pellizzoni, D. Zerla and I. Rimoldi, Eur. J. Inorg. Chem., 2012, 4365-4370.

51 M. N. Golovin, M. M. Rahman, J. E. Belmonte and W. P. Giering, Organometallics, 1985, 4, 1981-1991.

52 O. Kühl, Coord. Chem. Rev., 2005, 249, 693-704.

53 G. Pacchioni and P. S. Bagus, Inorg. Chem., 1992, 31, 4391-4398.

54 M. Mitoraj and A. Michalak, J. Mol. Model., 2007, 13, 347-355.

55 A. Michalak, M. Mitoraj and T. Ziegler, J. Phys. Chem. A, 2008, 112, 1933-1939.

56 M. P. Mitoraj, A. Michalak and T. Ziegler, J. Chem. Theory Comput., 2009, 5, 962-975.

57 R. F. Nalewajski, A. M. Köster and K. Jug, Theor. Chim. Acta, 1993, 85, 463-484.

58 R. F. Nalewajski and J. Mrozek, Int. J. Quantum Chem., 1994, 51, 187-200.

59 R. F. Nalewajski, J. Mrozek and A. Michalak, Int. J. Quantum Chem., 1997, 61, 589-601.

60 M. Radoń, Theor. Chem. Acc., 2008, 120, 337-339.

61 G. Frenking and F. Matthias Bickelhaupt, The EDA Perspective of Chemical Bonding, Wiley-VCH Verlag $\mathrm{GmbH} \& \mathrm{Co}$. KGaA, 2014, pp. 121-157.

62 L. Belpassi, I. Infante, F. Tarantelli and L. Visscher, J. Am. Chem. Soc., 2008, 130, 1048-1060.

63 S. Rampino, L. Storchi and L. Belpassi, J. Chem. Phys., 2015, 143, 024307.

64 G. Bistoni, S. Rampino, N. Scafuri, G. Ciancaleoni, D. Zuccaccia, L. Belpassi and F. Tarantelli, Chem. Sci., 2016, 7, 1174-1184. 